\title{
ANTIPROLIFERATIVE EFFECTS OF PSIDIUM GUAJAVA LEAF EXTRACT ON ORAL SQUAMOUS CARCINOMA CELLS
}

\begin{abstract}
SHARADA T RAJAN ${ }^{1 *}$, MALATHI N ${ }^{1}$, CHAMUNDEESWARI $\mathrm{D}^{2}$, ROSE $^{3}$
${ }^{1}$ Department of Oral Pathology, Faculty of Dental Sciences, Sri Ramachandra Institute of Higher Education and Research, Porur, Chennai, Tamil Nadu, India. ${ }^{2}$ Department of Pharmacognosy, Faculty of Pharmacy, Sri Ramachandra Institute of Higher Education and Research, Porur, Chennai, Tamil Nadu, India. ${ }^{3}$ Chief Scientist and Head (Retd.), Department of Biotechnology, CLRI, Chennai, Tamil Nadu, India. Email: dr.sharadaganesh@yahoo.co.in
\end{abstract}

Received: 16 November 2018, Revised and Accepted: 05 January 2019

\section{ABSTRACT}

Objective: Cancer is the major cause of mortality affecting population irrespective of age. Oral cancer is one among the various cancers affecting major population in India. To overcome toxicity of chemotherapy and disfiguration by surgical procedures, researchers are targeting phytochemicals for their anticancer properties. This study evaluates the antiproliferative effects of Psidium guajava leaf extract against OSC cells.

Methods: KB cells were purchased from NCCS, Pune. Extract from leaves of P. guajava was prepared with ethanol and evaluated with high-performance thin-layer chromatography (HPTLC). Antiproliferative effects of the extract were assessed with 3-(4,5-dimethyl-2-thiazolyl)-2,5-diphenyl--tetrazolium bromide (MTT) assay and flow cytometry.

Results: HPTLC revealed the presence of quercetin in the extract. MTT assay showed decreasing pattern in cell viability with the increasing dose of extract. Flow cytometry revealed the seizing of cycle by the extract.

Conclusion: The study results conclude the presence of antiproliferative properties in the leaf extract of $P$. guajava.

Keywords: Psidium guajava, Anticancer activity, Quercetin, Cytotoxicity, Flow cytometry.

(C) 2019 The Authors. Published by Innovare Academic Sciences Pvt Ltd. This is an open access article under the CC BY license (http://creativecommons. org/licenses/by/4. 0/) DOI: http://dx.doi.org/10.22159/ajpcr.2019.v12i3.30781

\section{INTRODUCTION}

Cancer is the most common non-communicable disease worldwide. Oral cancer is the sixth most common cancer in Indian population. It accounts for $86 \%$ of the world's oral cancer cases with a recurrence rate of $25 \%$, according to the National Institute of Public health, February 2011. Between 2007 and 2011, 5.3\% of cases were recorded in Tamil Nadu, of which $4.5 \%$ of cases were recorded from Chennai. Tobacco-related cancers account for $40-45 \%$ of all cancers in men and $15-20 \%$ of all cancers in women, in Chennai [1]. Cancer is due to sequential accumulation of genetic alterations termed as multistep oncogenesis, resulted by various endogenous and exogenous factors [2]. Histopathology of cancer structures revealed increased cell proliferation or decreased apoptosis or both [3-6]. Therapeutic targets were aimed at these various stages of oncogenesis. The surgical therapy of oral cancer is the most disfiguring, due to its wide excisional removal, while chemotherapy causes adverse cytological and systemic effects [7]. Natural products used in traditional folk medicine have been the source of many medically beneficial drugs, as many medicinal plants have been shown to present interesting biological and pharmacological activity [8]. The indigenous phytochemicals, apart from being easily available, are also less likely to produce much adverse effects that are associated with allopathic chemotherapy.

Psidium guajava is commonly called as guava and belongs to the family Myrtaceae. It is a food crop and also used in traditional folk medicine [9]. Various parts of P. guajava were used in folk medicine for the treatment of various human ailments such as wounds, ulcers, bowels, and systemic infections like cholera [10]. The whole plant or its roots were used in the form of infusion, decoction, and paste for analgesia in painful menstruations, miscarriages, uterine bleeding, premature labor, and wounds [11]. The bark was used as an astringent in the treatment of wounds and diarrhea in the Philippines. The root was used in West Africa, as a decoction to relieve diarrhea, toothaches, and cough. The decoction of the leaves was used as antispasmodic and for rheumatism in India [12]. The leaves of P. guajava were used in the USA, as an antibiotic in the form of decoction for wounds, ulcers, and toothache [13].

Oxidative injury due to free radicals or reactive oxygen species was implicated in the pathogenesis of numerous diseases including cancer. P. guajava leaf extracts have been found to be potential sources of natural oxidants such as ascorbic acid, quercetin, guavin, gallic acid, and caffeic acid [12]. The aqueous extract of $P$. guajava leaves inhibited the viability of cancer cell line (DU-145) with increase of dose. Essential oil extracted from P. guajava was also reported to be highly effective in reducing the growth of murine leukemia P388 [14]. The most active component found in the leaves of P. guajava is quercetin, a polyphenolic flavonoid molecule along with quercetin-3-o-glucopyranoside and morin [15]. Quercetin (3,3',4',5,7-pentahydroxyflavone; $\mathrm{R}=\mathrm{OH})$ belongs to an extensive class of polyphenolic flavonoid compounds almost ubiquitous in plants and plant food sources. Quercetin was shown to possess anticancer effects in various studies [16]. With these data, our study aims to investigate the anticancer effect of the leaves of P. guajava on oral squamous cell carcinoma cell lines with the hypothesis that the active ingredient(s) of the leaves of P. guajava inhibit the growth of cancer by the inhibition of the growth signals.

\section{METHODS}

\section{Plant collection}

Fresh leaves of $P$. guajava were collected from the medicinal herbal garden of the college and authenticated. The leaves were cleaned, dried under the shade, powdered, and stored for further processing.

Extraction and partial characterization of plant material The powdered crude extract was further processed using Soxhlet apparatus. The extraction process was done using $100 \%$ ethanol and $70 \%$ ethanol. The extract obtained by these two procedures was 
freeze-dried and stored in sterile containers. The final extract obtained with two methods, $100 \%$ ethanol and $70 \%$ ethanol were named as S1 and S2, respectively. These extracts were partially characterized and quantification done for quercetin in the extract using high-performance thin-layer chromatography (HPTLC) fingerprinting.

\section{HPTLC analysis}

Quantification of quercetin in the two extract forms of P. guajava was evaluated using HPTLC instrument (CAMAG, Muttenz, Switzerland). The system parameters included aluminum-coated silica gel TLC plate (Merck, Germany), mobile phase - isopropanol:water - 7:3, tungsten lamp to capture images at a wavelength of 300-600 nm. HPTLC method was performed after derivatization with $10 \%$ ammonium chloride.

About $1 \mathrm{mg} / \mathrm{ml}$ of the standard quercetin was prepared with methanol. From this, $50 \mu \mathrm{l}$ was diluted with $950 \mu \mathrm{l}$ of methanol, and hence, the concentration of the standard was $50 \mu \mathrm{g} / \mathrm{ml} .10 \mathrm{mg} / \mathrm{ml}$ of extracts sample S1 and S2 were prepared with $1 \mathrm{ml}$ of methanol to make the concentration of $10 \mathrm{mg} / \mathrm{ml}$. The adsorbent was silica gel $60 \mathrm{~F} 254$. The precoated TLC plate was heated in an oven for activation. $1 \mathrm{ml}$ of the standard flavonoid quercetin and the ethanol leaf extract were applied dried and then kept in the developing tank. The chamber was saturated with the solvents for $20 \mathrm{~min}$ at room temperature. After the development of the plate, it was air-dried, then the numbers of spots were noted and retention factor (Rf) values were calculated. Average peak area of the standard was calculated. The calibration curve of the standard drug concentration (X-axis) over the average peak height/area (Y-axis) was prepared to get a regression equation by Win Cats software. The mean peak height/area of the sample was calculated and the content of quercetin was quantified using the regression equation obtained from the standard curve.

\section{Cells and cell culture}

KB cell line was purchased from National Centre for Cell Sciences, Pune. RPMI 1640 media, trypsin, ethylenediaminetetraacetic acid, sodium bicarbonate, propidium iodide (PI), RNase, triton X-100, 3-(4,5-dimethyl-2-thiazolyl)-2,5-diphenyl--tetrazolium bromide (MTT), dimethyl sulfoxide (DMSO), penicillin, and streptomycin were purchased from Sigma-Aldrich. Fetal bovine serum and phosphate-buffered saline ( $\times 10)$ were purchased from Gibco, Invitrogen Life Technologies.

\section{MTT assay}

The assay was performed as described previously $[17,18]$. Cells $(1 \times 105 /$ well $)$ were plated in 24 -well plates and incubated in $37^{\circ} \mathrm{C}$ with $5 \% \mathrm{CO}_{2}$ condition. The extracts $\mathrm{S} 1$ and S2 were added and incubated for $24 \mathrm{~h}$. After incubation, the sample was removed from the well and washed with phosphate-buffered saline ( $\mathrm{pH} 7.4)$ or MEM without serum. $100 \mu \mathrm{l} /$ well $(5 \mathrm{mg} / \mathrm{ml})$ of $0.5 \%$ MTT was added and incubated for $4 \mathrm{~h}$. After incubation, $1 \mathrm{ml}$ of DMSO was added in all the wells. The absorbance at $570 \mathrm{~nm}$ was measured with UV spectrophotometer using DMSO as the blank. Measurements were performed and the concentration required for a $50 \%$ inhibition $\left(\mathrm{IC}_{50}\right.$ ) was determined graphically. The percentage cell viability was calculated using the following formula:

$$
\% \text { Cell viability }=\text { A570 of treated cells } / \text { A570 of control cells } \times 100
$$

Graphs were plotted using the percentage of cell viability at Y-axis and concentration of the sample in X-axis. Cell control and sample control are included in each assay to compare the full cell viability assessments.

\section{Flow cytometry assay}

After $80 \%$ confluency, cells were trypsinized and seeded in 6-well plates, then, incubated overnight and treated with extracts S1 and S2, and incubated for $24 \mathrm{~h}$. Then, the cells were washed with PBS, trypsinized, and centrifuged at $1200 \mathrm{rpm}$ for $5 \mathrm{~min}$. The collected pellets were suspended in PBS and fixed in ethanol. On the day of analysis, the cells were treated with RNase, PI, and processed in flow cytometer (BD FACSCalibur). The analysis was done with Cell Quest Pro software (Becton Dickinson, USA).
Flow cytometry offers a rapid method for measuring the DNA content of cells and provides a convenient research tool to monitor cell cycle status and regulation. An exponentially growing population of cells will have a DNA content distribution containing an initial peak of G0/G1 cells, a valley of $S$ phase cells, and a second peak containing G2/M cells. Cells in the G2/M phase have twice the DNA content as cells in the G0/G1 phase.

Forward angle scatter (FSC) is a measure of cell size. Side scatter (SSC) is a measure of cellular components or granularity. A dot plot showing FSC versus SSC (cell size and granularity) was drawn and fluorescence voltage channel was adjusted to allow the system to trigger on fluorescent particles. In the FSC versus SSC plot, cells were acquired between channels 200 and 800 . The lower level discriminator was adjusted to partially eliminate sample debris below the cell population and diploid G0-G1 peak at channel 200. A gate (R1) was drawn to show the total events. The emitted fluorescent light of the DNA dye (PI emits fluorescence in FL2 channel) generates an electronic signal that can be recorded as high $(\mathrm{FL} 2 \mathrm{H})$ for the intensity of the staining as well as measured as pulse-area (FL2A) and pulse-width (FL2W) of the samples. By plotting the FL2W versus FL2A in a dot plot graph, G1 doublet discrimination was made. In the FL2-width versus FL2-area dot plot, a gate (G0/G1/S/G2/M) was set around the single population. The instrument computes the data and presents various cell cycle phases in the form of an integrated histogram from which percentage of DNA content in each phase of cell cycle was calculated [19].

\section{RESULTS}

\section{HPTLC fingerprinting of S1 and S2}

The HPTLC analysis revealed the presence of quercetin in the two extract forms at proportion of $0.23 \%$ in S1 and $0.48 \%$ in S2. Quercetin detected by brown-yellow color zone. The Rf values of extract and standard were shown in Table 1 and chromatograms of S1, S2, and standard quercetin showing the area and peak values are depicted in Fig. 1.

\section{Antiproliferative activity of $P$. guajava \\ MTT assay}

MTT cytotoxicity assay revealed decreased cell viability of KB cells with increase in concentration of S1 and S2. The $\mathrm{IC}_{50}$ value for $\mathrm{S} 1$ was $12.5 \mu \mathrm{g} / \mathrm{ml}$ and for S2 was $6.25 \mu \mathrm{g} / \mathrm{ml}$. S2 extract showed effective cell proliferation inhibition at a lower dose as shown in Fig. 2.

\section{Flow cytometric analysis}

The effect of extracts S1 and S2 on cell cycle progression of KB cells is shown in Fig. 3. After the treatment period, there was decrease in

Table 1: Chromatogram peak table with $\mathrm{Rf}$ values, area and height of extract $S 1$ and $S 2$, and quercetin

\begin{tabular}{|c|c|c|c|c|c|}
\hline $\begin{array}{l}\text { S. } \\
\text { No. }\end{array}$ & Compound & R.F & Height & Area & $\lambda \max \mathbf{N M}$ \\
\hline 1 & S1 & 0.11 & 28.5 & 260.8 & 466 \\
\hline 2 & & 0.28 & 7.2 & 193.7 & 466 \\
\hline 3 & & 0.42 & 2.7 & 59.8 & 466 \\
\hline 4 & & 0.45 & 2.7 & 16.2 & 466 \\
\hline 5 & & 0.46 & 2.3 & 11.8 & 466 \\
\hline 6 & & 0.50 & 4.2 & 28.0 & 466 \\
\hline 7 & & 0.61 & 2.7 & 90.6 & 466 \\
\hline 8 & & 0.69 & 1.6 & 24.7 & 466 \\
\hline 9 & & 0.74 & 20.3 & 441.4 & 466 \\
\hline 10 & $\mathrm{~S} 2$ & 0.11 & 20.6 & 186.7 & 466 \\
\hline 11 & & 0.14 & 12.2 & 223.8 & 466 \\
\hline 12 & & 0.27 & 7.4 & 201.7 & 466 \\
\hline 13 & & 0.38 & 5.6 & 124.7 & 466 \\
\hline 14 & & 0.48 & 2.8 & 16.0 & 466 \\
\hline 15 & & 0.57 & 2.0 & 69.7 & 466 \\
\hline 16 & & 0.68 & 3.1 & 65.2 & 466 \\
\hline 17 & & 0.53 & 18.0 & 513.4 & 466 \\
\hline 18 & Standard quercetin & 0.40 & 39.8 & 4999.1 & 466 \\
\hline
\end{tabular}




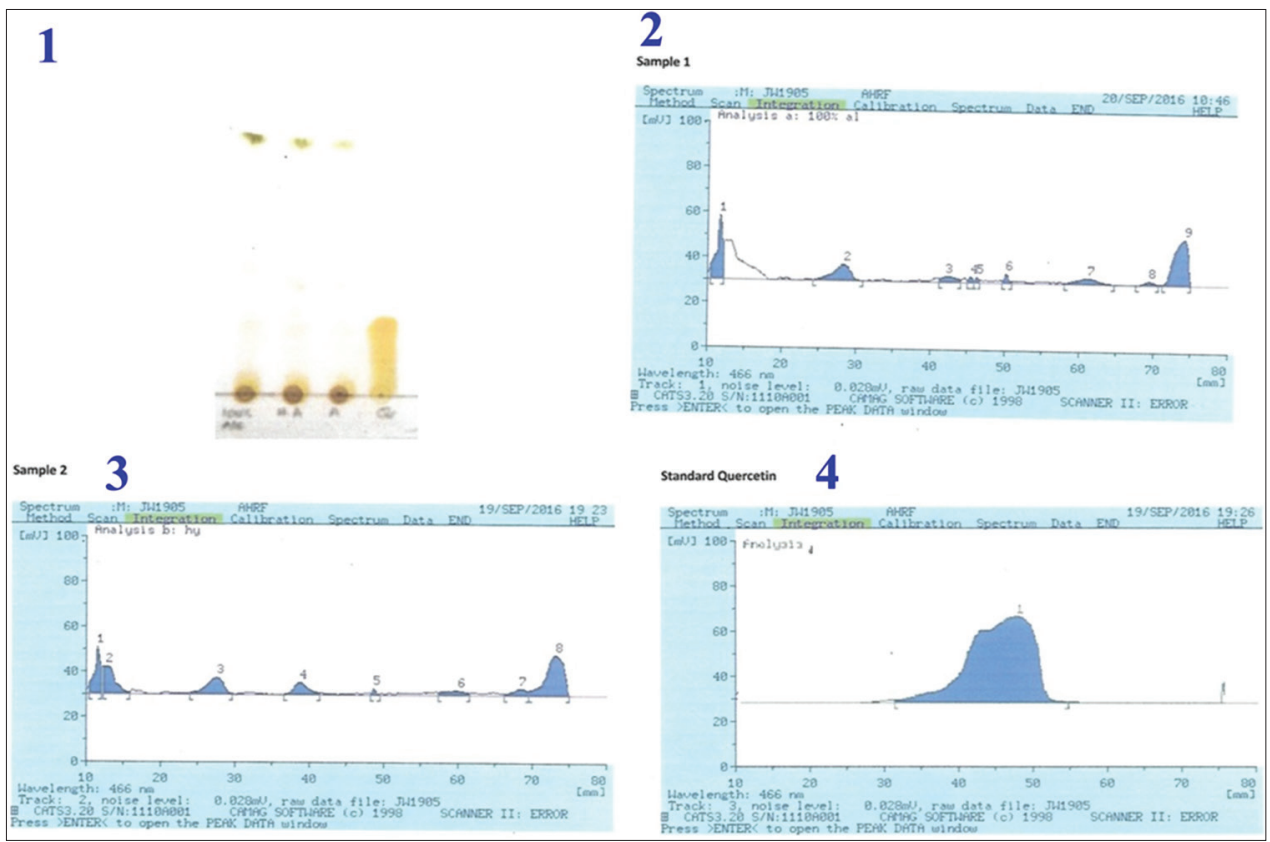

Fig. 1: High-performance thin-layer chromatography chromatogram of ethanolic extract at $466 \mathrm{~nm}$ showing different peaks (bands) of phytoconstituents in Psidium guajava and standard quercetin. Concentration of extracts $10 \mathrm{mg} / \mathrm{ml}$. 1: Chromatograms of extract in HPTLC analysis after derivatization with color zones, 2: Chromatogram of ethanolic extract S1, 3: Chromatogram of ethanolic extract S2, 4: Chromatogram of standard quercetin

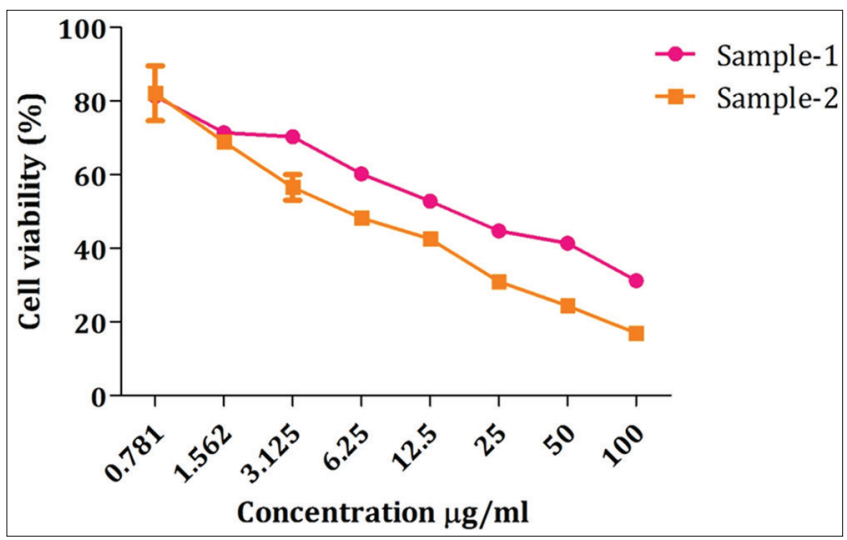

Fig. 2: 3-(4,5-Dimethyl-2-thiazolyl)-2,5-diphenyl--tetrazolium bromide assay, $50 \%$ inhibition $\left(\mathrm{IC}_{50}\right.$ ) value of the Psidium guajava leaf extracts $S 1$ and $S 2 . \mathrm{IC}_{50}$ of $\mathrm{S} 1-12.5 \mu \mathrm{g} / \mathrm{ml}$ and $\mathrm{S} 2-6.25 \mu \mathrm{g} / \mathrm{ml}$

G0/G1 phase cells from $87 \%$ (control/untreated) to $54 \%$ with S1 treatment and $41 \%$ with S2 treatment, decrease in S phase cells from $1.9 \%$ (control/untreated) to $0.19 \%$ with S1 treatment and $0.09 \%$ with $\mathrm{S} 2$ treatment, decrease in G2/M phase cells from $2.92 \%$ to $0.14 \%$ with $\mathrm{S} 1$ treatment and $0.08 \%$ with S2 treatment. The decreased G2/M phase cells signify arrested cell growth or cycle. Flow cytometric scatterplots showed increased apoptosis with both extracts S1 and S2 compared to control/untreated cells.

\section{DISCUSSION}

Cancer remains one of the leading causes of death worldwide. Many cancer therapies are in research which includes the use of natural products from plants [20]. There is a need to find out novel, effective and scientifically reliable phytochemicals are urgent. Natural products provide a fertile ground for seeking out treatments with fewer side effects and equal or better efficacy. The pharmacological effects of plant products were due to their constituent phytochemicals that include carbohydrates [21], carotenoids, polyphenols, alkaloids, and sulfur-/nitrogen-containing compounds [22]. Phytochemicals extracted from plants are excellent pharmacological agents and they are easily available, non-toxic, inexpensive, and well tolerated [23].

The aim of the present study was to assess the antiproliferative effects of the leaf extracts S1 and S2 of P. guajava on oral squamous cell carcinoma cells and to propose the possible mechanism of action of the anticancer effect of the same. KB cells were reported to have high proliferative activity and they are undifferentiated in nature [24]. Some plant antioxidants have been suggested to contribute to their anticarcinogenic effects and their flavanols have been reported to inhibit cancer cell proliferation in vitro [25]. S2 showed more proportion of quercetin composition compared to S1. Commercially available quercetin was found to downregulate expression of mutant p53 protein, thereby causing an arrest of cells in the G2-M phase of the cell cycle. Mutations of p53 are among the most common genetic abnormalities in human cancers. The G1 checkpoint controlled by the p53 gene is a major site for the control of cellular proliferation. Quercetin has been found to arrest human leukemic T cells in the late G1 phase of the cell cycle. Quercetin has also been found to inhibit production of heat shock proteins in colon cancer. Heat shock proteins along with mutant p53 form a complex which allows tumor cells to bypass normal mechanisms of cell cycle arrest. Heat shock proteins also allow for improved cancer cell survival under different bodily stresses and are associated with shorter disease-free survival and chemotherapy drug resistance. Quercetin has also been found to inhibit the expression of p21 ras oncogene in colon cancer cell lines. This mutation which causes continuous activation of the signal for DNA replication has also been implicated in a number of human cancers. Quercetin was also found to inhibit the expression of tyrosine kinase involved in the transduction of growth factor signals to the nucleus. It also binds to type II estrogen receptor, thereby offering a greater growth inhibition of ER-negative cells [16]. Both the extracts arrested cells of G2/M phase and G1 phase as revealed by above-described studies with other antiproliferative agents and cancer cells. In comparison, S2 extract was more effective than S1. S2 decreased G1 phase cells to $41 \%$ and G2/M phase cells to $0.08 \%$ which may be correlated to composition of quercetin in the extract. Both the extracts S1 and S2 have shown antiproliferative effects in the KB cells. 

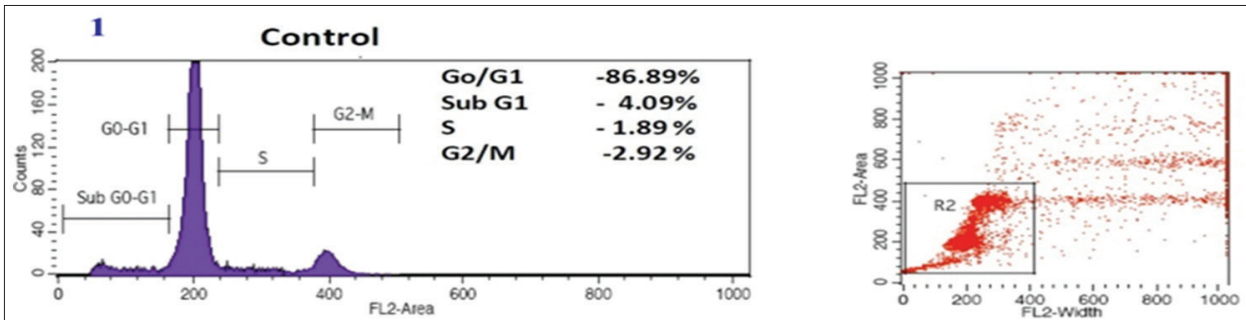

2
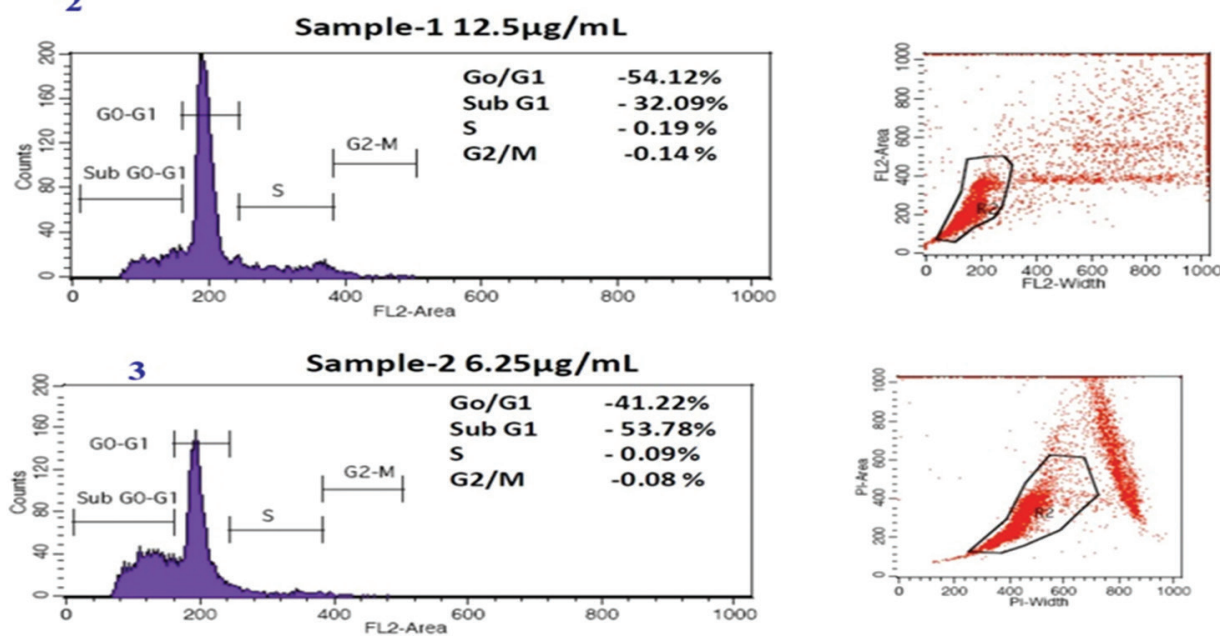

Fig. 3: Flow cytometric analysis of apoptosis in KB cells. KB cells were treated with the corresponding $\mathrm{IC}_{50}$ concentrations of S1 and S2 and stained with propidium iodide (PI) dye and analyzed by flow cytometry. Flow cytometric patterns of 1: Untreated cells, 2: S1, and 3: S2

\section{CONCLUSION}

The results of the present study conclude the antiproliferative effect of $P$. guajava leaf extract. Active chromatographic fractions induced apoptosis and also arrested cell cycle. Further studies are required to identify the active ingredient, which can be developed as a chemotherapeutic neutraceutical with further clinical trials.

\section{ACKNOWLEDGMENTS}

The authors would like to sincerely thank the management, Sri Ramachandra Institute of Higher Education and Research, Chennai, for providing the state of art research and library facilities required for the completion of the study.

\section{AUTHORS' CONTRIBUTIONS}

Dr. Sharada, the principal investigator of the project, performed the sample collection and prepared the manuscript. Dr. Malathi, Guide, Prof., and Head of the Department, is the coinvestigator of the project and helped in conceptual designing of the study and supervised and edited the manuscript preparation. Dr. Chamundeeswari and Dr. C. Rose, research advisors, guided in analysis of the results and helped in reviewing the manuscript.

\section{CONFLICTS OF INTEREST}

The authors declare that they have no conflicts of interest.

\section{REFERENCES}

1. Swaminathan R, Shanta V, Ferlay J, Balasubramanian S, Bray F, Sankaranarayanan R. Trends in cancer incidence in Chennai city (1982-2006) and statewide predictions of future burden in Tamil Nadu (2007-16). Natl Med J India 2011;24:72-7.

2. Lee SB, Park HR. Anticancer activity of guava (Psidium guajava L.) branch extracts against HT-29 human colon cancer cells. J Med Plants Res 2010;4:891-6.
3. He Y, Wen J, Cui Q, Lai F, Yin D, Cui H. Quantitative evaluation of in vivo target efficacy of anti-tumor agents via an immunofluorescence and edulabeling strategy. Front Pharmacol 2018;9:812.

4. Hanahan D, Weinberg RA. The hallmarks of cancer. Cell 2000;100:57-70.

5. Pandey SS, Singh S, Pathak C, Tiwari BS. Programmed cell death: A process of death for survival-how far terminology pertinent for cell death inunicellularorganisms. JCellDeath 2018;11:1179066018790259.

6. Kerr JF, Wyllie AH, Currie AR. Apoptosis: A basic biological phenomenon with wide-ranging implications in tissue kinetics. Br J Cancer 1972;26:239-57.

7. Hsu S, Singh B, Schuster G. Induction of apoptosis in oral cancer cells: Agents and mechanisms for potential therapy and prevention. Oral Oncol 2003;1:1-13.

8. Balsundaram A, Chellathai D. Evaluation of acute and chronic toxicity, cognition in adult zebra fish with vasicine; A prospective cognition enhancer in neurological disorders. Int J Pharm Biol Sci 2016;7:298-302.

9. Devasagayam TP, Sainis KB. Immune system and antioxidants, especially those derived from Indian medicinal plants. Indian J Exp Biol 2002;40:639-55.

10. Begum S, Hassan SI, Siddiqui BS. Two new triterpenoids from the fresh leaves of Psidium guajava. Planta Med 2002;68:1149-52.

11. Gutierrez RM, Mitchell S, Solis RV. Psidium guajava: A review of its traditional uses, phytochemistry and pharmacology. J Ethnopharmacol 2008;117:1-27.

12. Sanda KA, Grema HA, Geidam YA, Bukar-Kolo YM. Pharmacological aspects of Psidium guajava: An update. Int J Pharmacol 2011;2011:1-9.

13. Leonti M, Vibrans H, Stiche O, Heinrich M. Ethnopharmacology of the popoluca, Mexico: An evaluation. J Pharm Pharmacol 2001;53:1653-69.

14. Salib JY, Michael HN. Cytotoxic phenylethanol glycosides from Psidium guajava seeds. Phytochemistry 2004;65:2091-3.

15. Tachakittirungrod S, Ikegami F, Okonogi S. antioxidant principles isolated from Psidium guajava grown in Thailand. Sci Pharm 2007:75:179-93.

16. Lamson WD, Brignall MS. Antioxidants and cancer III: Quercetin. Alt Med Rev 2000;5:196-208.

17. Mossman T. Rapid colorimetric assay for cellular growth and survival: Application to proliferation and cytotoxicity assays. J Immunol Methods 1983;65:55-63.

18. Haridas R. In-vitro cytotoxicity activity of malaxis rheedei SW 
methanol extract against Hela cell line and MCF-7 cell line. Asian J Pharm Clin Res 2016;9:244-6.

19. Yusnita Y, Masfria M, Rosidah R, Iksen I. Effect of hexane fraction from papaya (Carica papaya L.) Male flower on cell cycle of colon adenocarcinoma (WIDR) cell and its combination index with doxorubicin. Asian J Pharm Clin Res 2018;11:138-40.

20. Wicaksono BD, Handoko YA, Arung ET, Kusuma IW, Yulia D, Pancaputra AN, et al. Antiproliferative effect of the methanol extract of Piper crocatum Ruiz and pav leaves on human breast (T47D) cells in vitro. Trop J Pharm Res 2009;8:28.

21. Ghanta M, Panchanathan E, Lakkakula B, Narayanaswamy A, Abhinand PA, Antony S. Molecular docking analysis of phytoconstituent from Momordica charantia with guanylate cyclase catalytic domain.
Bioinformation 2018;14:378-83.

22. Karna P, Gundala SR, Gupta MV, Shamsi SA, Pace RD, Yates C, et al. Polyphenol-rich sweet potato greens extract inhibits proliferation and induces apoptosis in prostate cancer cells in vitro and in vivo. Carcinogenesis 2011;32:1872-80

23. Sak K. Chemotherapy and dietary phytochemical agents. Chemother Res Pract 2012;2012:282570.

24. Kawahara E, Okada Y, Nakanishi I, Iwata K, Kojim S, Kumagai S, et al. The expression of invasive behavior of differentiated squamous carcinoma cell line evaluated by an in vitro invasion model. Jpn J Cancer Res Gann 1993;84:409-18.

25. Scalbert A, Johnson IT, Saltmarsh M. Polyphenols: Antioxidants and beyond. Am J Clin Nutr 2005;81:215s-7. 